\title{
SECAGEM INFRAVERMELHO DE CAROÇOS DE AÇAÍ PARA A OBTENÇÃO DE BIOMASSA
}

\author{
A. M. BARBOSA NETO ${ }^{1}$, J. O. LIMA $^{2}$, L. G. MARQUES ${ }^{3}$ e M. M. PRADO ${ }^{3}$ \\ ${ }^{1}$ Universidade Estadual de Campinas, Faculdade de Engenharia Mecânica \\ ${ }^{2}$ Universidade Estadual de Campinas, Faculdade de Engenharia Química \\ ${ }^{3}$ Universidade Federal de Sergipe , Departamento de Engenharia Química \\ E-mail para contato: manoelprado@ufs.br
}

\begin{abstract}
RESUMO - A secagem é uma etapa essencial nas tecnologias de conversão térmica de biomassa, como pré-tratamento para os processos de pirólise, gaseificação e combustão, bem como para sua preservação em períodos relativamente longos de armazenamento. No entanto, essa fase de processamento não pode se mostrar onerosa na contabilização dos custos energéticos. Logo, o objetivo deste trabalho foi analisar a secagem de biomassa constituída por caroços residuais do processamento do açaí, num secador infravermelho (IV), através de uma abordagem experimental dos aspectos relacionados à transferência de calor e massa e ao consumo energético do processo. A caracterização física do material, em termos de tamanho e forma de partículas, foi primeiramente realizada, via análise de imagens. Em seguida, os experimentos de secagem IV em camada fina e avaliação do consumo energético do secador foram realizados para as temperaturas da fonte de 80,100 e $120^{\circ} \mathrm{C}$ e distância entre a fonte de aquecimento IV e a amostra de $17 \mathrm{~cm}$. A secagem IV de caroços de açaí em camada fina ocorreu nos períodos de aquecimento e de densidade de fluxo de massa decrescente. $\mathrm{O}$ consumo energético para se atingir um teor de umidade em torno de $10 \%$ (b.u) ficou entre 64 e $37 \mathrm{MJ} / \mathrm{kg}$ na faixa operacional investigada.
\end{abstract}

\section{INTRODUÇÃO}

A busca por fontes renováveis de energia cresce a cada dia, diante das preocupações com o aquecimento global e com o esgotamento dos combustíveis fósseis. A biomassa é uma das mais importantes fontes renováveis de energia primária, por causa das baixas emissões de dióxido de carbono que podem afetar o clima global. Ela mostra grande potencial como fonte sustentável de matéria prima para a combustão e co-combustão com carvão, a produção de gás de síntese por gaseificação, produção de bio-óleo por pirólise e produção de bioetanol por fermentação (Wang et al., 2008).

Diante do crescente aumento no processamento de frutos de açaí para atender às demandas dos mercados interno e externo, as atenções têm sido direcionadas para o aproveitamento de seus caroços como biomassa para geração de energia. Os resultados obtidos no trabalho de Nagaishi (2007) sobre o uso das estruturas do açaí (cacho, folha, estirpe, caroço) para fins de geração de energia indicam o caroço, resíduo sólido do processamento do fruto de açaí, como a fonte mais promissora de energia de biomassa, pois além de apresentar melhores características físicas, químicas e térmicas, em comparação com as demais analisadas (cacho, folha e estipe), apresenta melhor material para o manuseio e maior disponibilidade, diferente do cacho e folha, que 
necessitariam sofrer uma densificação, assim como também as folhas e estipes que não são de fácil obtenção.

O teor de umidade da biomassa é um dos principais fatores que limitam a sua aplicação como um combustível alternativo, devido aos altos custos de transporte, às dificuldades de armazenamento e à redução da eficiência térmica durante a conversão de energia (Liu et al., 2014). Um alto teor de umidade na biomassa reduz a temperatura de combustão, causando combustão incompleta e produtos de reação indesejáveis, aumentando a emissão de gases poluentes (Gebreegziabher et al., 2013). Além disso, um biocombustível com elevado teor de umidade requer uma grande quantidade de combustível auxiliar para se tornar mais inflamável (Khan et al., 2009).

Segundo Kaliyan e Morey (2009), o teor de umidade da biomassa deve ser reduzido para valores entre $8-10 \%$ b.u., antes da densificação e conversão de energia para uso econômico. A secagem é, portanto, uma etapa essencial nas tecnologias de conversão térmica de biomassa, como pré-tratamento para os processos de pirólise, gaseificação e combustão, e também para preservar a biomassa em períodos relativamente longos de armazenamento. No entanto, o alto consumo de energia do processo de secagem também é a principal barreira para tornar a biomassa competitiva com produção de energia de qualidade. Logo, o desenvolvimento de secadores eficientes e compactos é de fundamental importância para viabilizar economicamente o uso da biomassa como fonte de biocombustível.

Neste sentido, a aplicação de tecnologias que fazem uso do fornecimento de energia eletromagnética, como a radiação infravermelho, (IV) aparece como uma alternativa potencial para aumentar a eficiência do processo de secagem de biomassa. Dentre as principais vantagens da secagem infravermelho estão: (a) a simplicidade do equipamento requerido; (b) a fácil incorporação do aquecimento IV com outros métodos de aquecimento (convectivo, condutivo e microondas); (c) o fácil direcionamento da fonte de calor e transferência da energia eletromagnética na região do infravermelho para a superfície do material sem aquecimento do ar; (d) a obtenção de altas taxas de transferência de calor com aquecedores compactos; (e) a reduzida necessidade de uma alta velocidade do ar, minimizando o contato do material submetido à secagem com o oxigênio; (f) a alta qualidade dos produtos finais e, (g) o menor tempo de processamento e a significativa economia de energia (Barbosa Neto et al., 2014).

Entre os fatores envolvidos no projeto de secadores IV, uma adequada predição das taxas de secagem é requerida. Esta informação é usualmente obtida a partir de estudos de secagem em camada fina, que possibilita o conhecimento da cinética de secagem do material em condições controladas do processo, fornecendo informações úteis sobre os mecanismos de transporte de umidade, a influência das condições operacionais sobre o comportamento de secagem e definição das condições de secagem ótimas para um menor consumo de energia. Vários trabalhos têm sido publicados sobre a secagem IV de diversos produtos incluindo desde sementes, grãos, vegetais, pigmentos e filmes poliméricos, até mesmo subprodutos agroindustriais (Barbosa Neto et al., 2014; Niamnuy et al., 2012; Khir et al., 2011; Boudhrioua et al., 2009; Ruiz Celma et al., 2009; Pawar et al., 2008; Kajtna et al., 2008). Entretanto, informações sobre a aplicação da radiação IV para a secagem de biomassa constituída por caroços de açaí não se encontram disponíveis na literatura.

Ademais, o uso de tecnologias radiantes é particularmente válido para materiais com alto 
teor de umidade, como é o caso do resíduo sólido do processamento do fruto do açaí, para os quais a radiação IV é quase totalmente absorvida pela umidade, enquanto o material seco é altamente permeável a tal radiação (Ruiz Celma et al., 2009). Diante desse contexto, o objetivo do presente trabalho foi determinar as características de secagem IV e de encolhimento da biomassa constituída por caroços residuais do processamento do açaí, bem como avaliar o potencial da técnica para reduzir o consumo de energia do processo, tornando o uso da biomassa do açaí viável economicamente para a produção de bioenergia.

\section{MATERIAIS E MÉTODOS}

\subsection{Materiais}

O material utilizado nos experimentos foram caroços de frutos de açaí (Euterpe Oleracea Mart.) obtidos na Fazenda Boa Esperança no município de Alto Alegre do Pindaré - MA. O produto foi lavado e armazenado em refrigerador a $-5^{\circ} \mathrm{C}$ a fim de manter as condições do produto in natura para a realização dos experimentos.

Para facilitar o despolpamento dos frutos, os mesmos foram descongelados durante uma hora antes de sua imersão em um banho a $45^{\circ} \mathrm{C}$. Após o banho, o qual durou $40 \mathrm{~min}$, seguiu-se o processo de despolpamento para a obtenção dos caroços, os quais ainda foram lavados para a retirada do restante da borra, em seguida os caroços foram enxutos com papel-toalha para a remoção da umidade superficial decorrente da lavagem.

Para caracterizar os caroços de açaí foram medidas as dimensões características (diâmetros do eixo maior e do eixo menor) de 250 caroços com a utilização de um micrômetro digital (marca Pantec; modelo 13111-25, com precisão de $10^{-3} \mathrm{~mm}$ ). A partir das dimensões medidas, foi possível obter uma distribuição normal do tamanho dos caroços e identificar que a faixa de tamanho de partícula presente em maior fração no material coletado, a qual foi utilizada em todos os experimentos de secagem visando minimizar o efeito da variabilidade do tamanho da partícula sobre os fenômenos de transferência envolvidos. A faixa de diâmetro máximo de 12 a $13 \mathrm{~mm}$ foi a que apresentou maior porcentagem de partículas na amostra, em torno de 56,6\%. Portanto, as amostras utilizadas nos testes de secagem foram selecionadas dentro dessa faixa.

\subsection{Secagem infravermelho}

Os experimentos de secagem foram realizados numa unidade constituída por uma lâmpada com emissão de raios infravermelhos de $250 \mathrm{~W}$, conforme detalhado em Barbosa Neto et al. (2011), e uma balança analítica para registrar a perda de massa do material. A distância entre a lâmpada infravermelho e a monocamada de partículas foi fixada em $17 \mathrm{~cm}$. As temperaturas da fonte de aquecimento IV empregadas foram de 80,100 e $120^{\circ} \mathrm{C}$, sendo todos os experimentos realizados em quadruplicata.

Para a determinação da cinética de secagem do material, foram feitas pesagens da amostra de sementes em intervalos de tempo pré-determinados, obtendo-se a massa de água evaporada por diferença das pesagens efetuadas. A temperatura da superfície das sementes foi também medida ao longo do processo com o auxílio de um pirômetro óptico digital (Impac, precisão $0,1^{\circ} \mathrm{C}$ ). Ao final de cada experimento, a massa de sólido seco foi determinada pelo método direto da estufa, com temperatura de $(105,0 \pm 3,0)^{\circ} \mathrm{C}$ por 24 horas. 
A fim de avaliar o encolhimento dos caroços de açaí durante o processo de secagem, suas dimensões foram medidas por meio de análise de imagens, utilizando o software Image ProPlus ${ }^{\circledR}$.

O consumo de energia foi quantificado por meio um multímetro como alicate amperímetro e um multímetro com a função de voltímetro, ambos da marca Minipla. A partir da voltagem e da média das correntes medidas, foi calculada a potência.

\subsection{Tratamento e análise dos dados}

Análise do encolhimento das partículas: 0 encolhimento durante a secagem foi quantificado a partir das alterações de volume e área superficial das partículas, as quais foram calculadas com base nas suas dimensões medidas por análise de imagens. Considerando a geometria do caroço de açaí como a de um esferóide oblato, a área superficial e o volume de cada partícula foram calculados a partir das seguintes equações:

$$
\begin{aligned}
& A=\pi\left[2 a^{2}+\frac{b^{2}}{e} \log \left(\frac{1+e}{1-e}\right)\right] \\
& e=\frac{\sqrt{a^{2}-b^{2}}}{a} \\
& V=\frac{4}{3} \pi a^{2} b
\end{aligned}
$$

O fenômeno foi avaliado com base nas razões de encolhimento volumétrico e superficial, $\left(\mathrm{V}_{\mathrm{p}} / \mathrm{V}_{\mathrm{p} 0)}\right.$ e $\left(\mathrm{A}_{\mathrm{p}} / \mathrm{A}_{\mathrm{p} 0}\right)$, respectivamente, plotadas em função do adimensional de umidade, constituindo as chamadas curvas de encolhimento. Deve ser ressaltado que a análise do encolhimento com base nas alterações de volume e área, a partir de medidas geométricas, foi suficientemente preciso, à medida que os caroços de açaí mantiveram praticamente sua forma original ao longo do processo de secagem

Análise da cinética de secagem: Os dados cinéticos de secagem foram inicialmente expressos em termos da temperatura e teor de umidade da partícula em função do tempo. A partir dos dados de teor de umidade em função do tempo, os valores de taxa de secagem (-dX/dt) foram obtidos por derivação numérica. A densidade de fluxo de umidade foi calculada a partir dos dados de taxa de secagem, massa de sólido seco e área da amostra.

Os dados do teor de umidade foram também convertidos em valores do adimensional de umidade (XR), definido como a razão entre a quantidade de água livre a ser removida num dado tempo e da água livre total disponível inicialmente. Admitiu-se que a prolongada exposição do material à radiação IV levaria à completa remoção de sua umidade, logo $\mathrm{X}_{\mathrm{e}}$ foi considerado zero, de acordo com Fasina et al. (2001).

A transferência de massa durante a secagem dos caroços de açaí foi analisada em termos da difusividade efetiva, a qual foi determinada em cada temperatura da fonte IV ao aplicar o modelo difusivo para descrever a cinética de secagem do material, sob a consideração do fenômeno de encolhimento das partículas. A solução analítica em coordenadas esféricas, assumindo 
encolhimento, processo isotérmico, difusão radial simétrica e considerando apenas o primeiro termo pode ser aproximada para a forma (Souraki e Mowla, 2008):

$$
Y R=\frac{X / V}{X_{0} / V_{0}}=\frac{6}{\pi^{2}} \exp \left(\frac{-\pi^{2} \cdot D^{*}{ }_{e f f} \cdot t}{R^{2}}\right)
$$

Sendo V o volume do material em um dado tempo $\left(\mathrm{m}^{3}\right) ; \mathrm{V}_{0}$ o volume inicial do material $\left(\mathrm{m}^{3}\right)$; R o raio do caroço de açaí em um dado tempo (m); $\mathrm{D}^{*}$ eff a difusividade efetiva considerando o encolhimento $\left(\mathrm{m}^{2} / \mathrm{s}\right)$ e $\mathrm{t}$ o tempo do processo (s). A dependências de $D_{\text {eff }}^{*}$ em relação à temperatura foi investigada ao plotar os valores obtidos em função da temperatura de secagem e ajustar uma equação do tipo Arrhenius aos dados.

O desempenho do secador infravermelho será avaliado com base no consumo de energia específico, definido como a energia requerida para reduzir a umidade inicial da biomassa, até um valor considerado ideal para o armazenamento e conversão de energia, 0,10 b.u. A energia específica será expressa em MJ/kg de umidade removida e $\mathrm{MJ} / \mathrm{kg}$ de sólido seco.

\section{RESULTADOS E DISCUSSÃO}

\subsection{Características de encolhimento}

Os resultados típicos das razões de encolhimento volumétrico $\left(\mathrm{V}_{\mathrm{p}} / \mathrm{V}_{\mathrm{p} 0}\right)$ e superficial $\left(\mathrm{A}_{\mathrm{p}} / \mathrm{A}_{\mathrm{p} 0}\right)$ dos caroços de açaí em função do adimensional de umidade (XR), em diferentes temperaturas de secagem são apresentados nas Figuras 1 e 2, respectivamente.

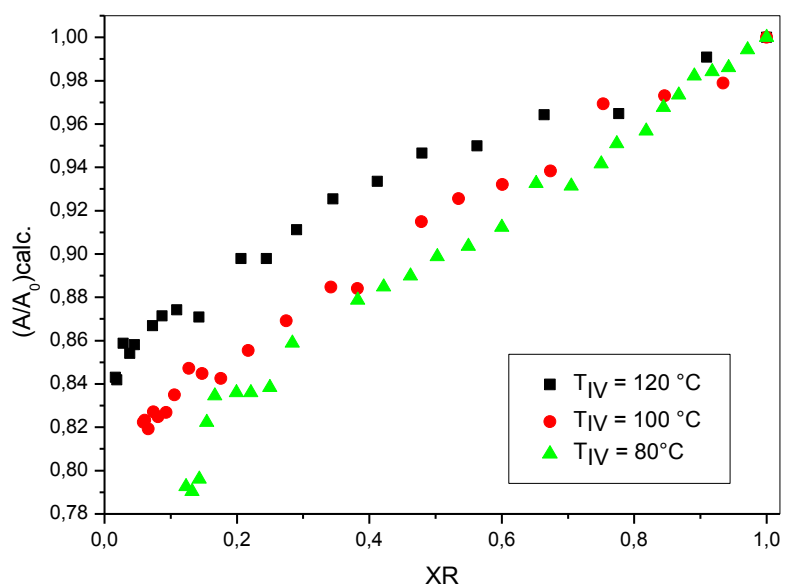

Figura 1 - Razão de encolhimento superficial 1 em função do adimensional de umidade.

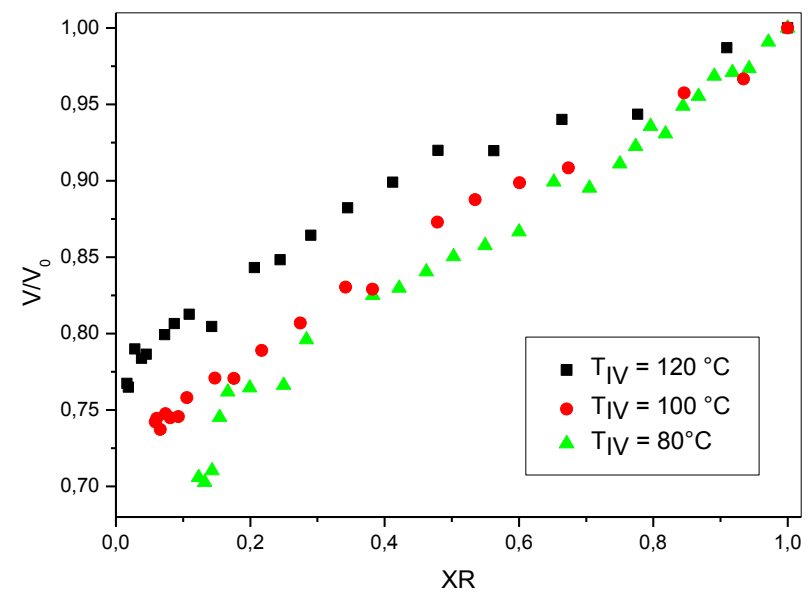

Figura 2 - Razão de encolhimento volumétrico em função do adimensional de umidade.

Verifica-se que encolhimento apresentado pelos caroços de açaí sofreu influência da temperatura da fonte de aquecimento IV e que o material apresentou reduções de área e volume praticamente lineares com relação ao decréscimo do teor de umidade. Esse comportamento linear indica que a contração de volume da partícula é proporcional à perda de umidade. A exposição dos caroços a elevadas intensidades de radiação IV pode ter contribuído para a formação de "case hardening" na superfície das partículas, limitando assim o seu encolhimento em altas temperaturas. A contração de volume e a redução na área superficial das partículas foram de $(26,1$ $\pm 2,2) \%$ e $(18,0 \pm 1,8) \%$, respectivamente, apontando a necessidade de levar em consideração as 
alterações na área de transferência para o cálculo da densidade de fluxo de umidade, bem como para incluir o fenômeno de encolhimento nos modelos de transferência de massa.

\subsection{Características de secagem}

Nas Figuras 3 e 4 encontram-se apresentados, respectivamente, os resultados de evolução de temperatura das partículas ao longo do processo de secagem IV em camada fina e de densidade de fluxo de umidade em função do adimensional de umidade, em diferentes temperaturas da fonte IV.

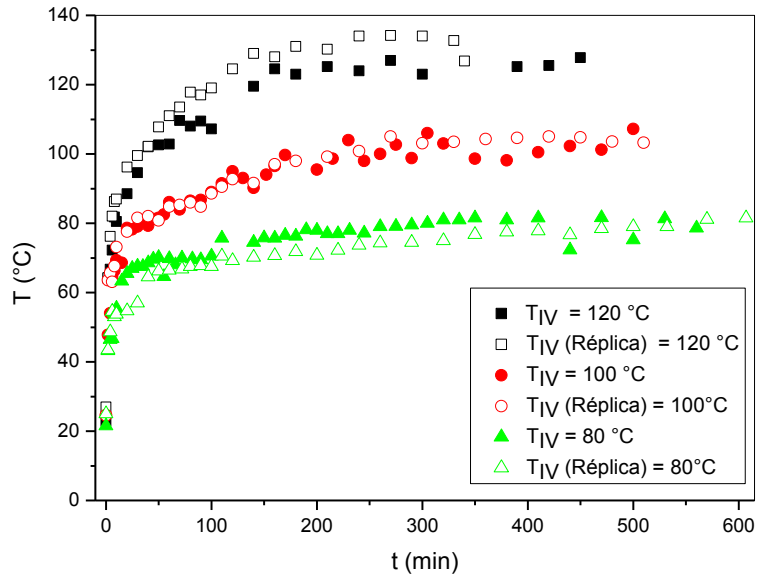

Figura 3- Temperatura superficial dos caroços de açaí em função do tempo, em diferentes temperaturas da fonte IV.

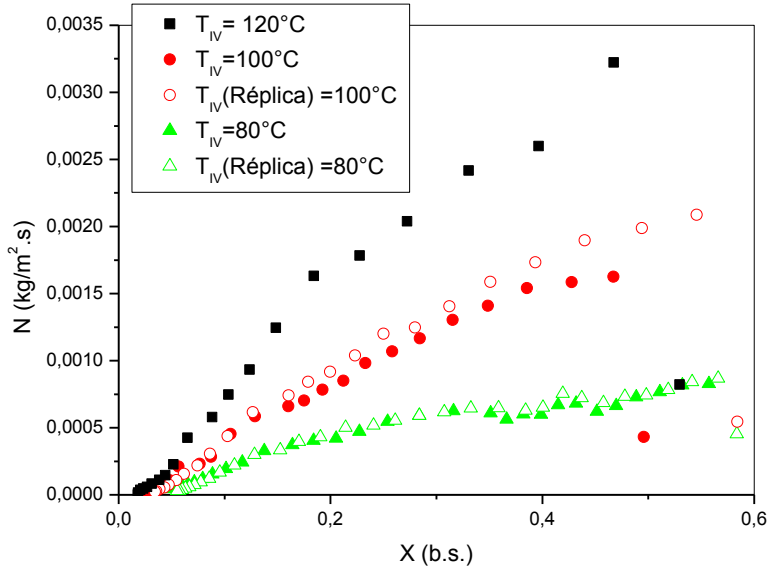

Figura 4 - Densidade de fluxo de umidade em função do adimensional de umidade, em diferentes temperaturas da fonte IV.

No início do processo, pode ser observado um rápido aumento do fluxo de secagem que está associado a um aumento da temperatura da superfície das partículas. Após esse rápido período de aquecimento, não há nenhum patamar correspondente à temperatura de bulbo úmido que denote a presença de um período de fluxo constante. Este comportamento evidencia que a superfície das partículas expostas à radiação IV seca muito rapidamente, de modo que a migração interna de umidade não supre a evaporação na superfície. Com a formação de regiões secas na superfície do material, logo no início da secagem, parte da energia eletromagnética fornecida continua a ser utilizada na forma de calor sensível e a temperatura na superfície tende a aumentar assintoticamente até a temperatura da fonte de IV. Nesse período há a queda da densidade de fluxo de umidade e a difusão de umidade no interior do sólido é o principal mecanismo físico governando a transferência de massa na secagem.

O aumento da intensidade de radiação eletromagnética sobre as partículas, provocado pela elevação da temperatura da fonte de aquecimento IV resultou num aumento da temperatura das partículas e, consequentemente, da pressão de vapor dentro das partículas, o que levou a maiores densidades de fluxo de umidade do material.

Os valores de difusividade efetiva estimados pelo modelo difusivo levando em consideração o encolhimento das partículas são apresentados na Tabela 1.

Os valores obtidos para a difusividade estão dentro da faixa de $10^{-11}$ a $10^{-9} \mathrm{~m}^{2} / \mathrm{s}$ reportada para materiais alimentares (Zogzas et. al., 1996). Barbosa Neto et. al. (2011) estudaram as características da secagem de açaí e verificaram que a difusividade efetiva considerando o 
encolhimento do fruto inteiro está na faixa de 3 a $12 \times 10^{-11} \mathrm{~m}^{2} / \mathrm{s}$, enquanto que na secagem do caroço de açaí, conforme mostrado na Tabela 1, a difusividade efetiva fica na faixa de 2 a $7 \times 10^{-10}$ $\mathrm{m}^{2} / \mathrm{s}$. Esse aumento na difusividade se deve à ausência da polpa e da parte fibrosa do fruto, diminuindo assim a resistência à transferência de massa no material. A dependência da difusividade efetiva com a temperatura da fonte de aquecimento IV foi descrita por uma relação do tipo Arrhenius. Desta forma, a energia de ativação encontrada para os caroços de açaí foi de aproximadamente $32,6 \mathrm{~kJ} / \mathrm{mol}$, que está contida no domínio de 12,7 a $110 \mathrm{~kJ} / \mathrm{mol}$ reportado para vários materiais agrícolas (Celma et al., 2009). O fator pré-exponencial foi de $1,35.10^{-5} \mathrm{~m}^{2} / \mathrm{s}$, com $\mathrm{R}^{2}$ igual a 0,9077 .

Tabela 1 - Coeficiente de difusão efetiva para cada temperatura do processo.

\begin{tabular}{|c|c|c|}
\hline $\mathrm{T}_{\mathrm{IV}}\left({ }^{\circ} \mathrm{C}\right)$ & $\mathrm{D}_{\text {eff }} \times 10^{10}\left(\mathrm{~m}^{2} / \mathrm{s}\right)$ & $\mathrm{R}^{2}$ \\
\hline 80 & 2,154 & 0,9942 \\
\hline 100 & 3,374 & 0,9918 \\
\hline 120 & 6,700 & 0,9939 \\
\hline
\end{tabular}

\subsection{Consumo de energia do secador IV}

Na Tabela 2 são apresentados os resultados típicos do consumo de energia específica, expressa em MJ por $\mathrm{kg}$ de água removida, bem como em MJ por $\mathrm{kg}$ de sólido seco, para todas as temperaturas da fonte de aquecimento IV empregadas.

Tabela 2 - Consumo de energia na secagem infravermelho de caroços de açaí.

\begin{tabular}{|c|r|c|}
\hline $\mathrm{T}_{\mathrm{IV}}\left({ }^{\circ} \mathrm{C}\right)$ & $\mathrm{E}\left(\mathrm{MJ} / \mathrm{kg} \mathrm{H}_{2} \mathrm{O}\right)$ & $\mathrm{E}(\mathrm{MJ} / \mathrm{kg}$ sól. seco \\
\hline 80 & $64,2 \pm 3,6$ & $23,5 \pm 3,8$ \\
\hline 100 & $49,3 \pm 6,7$ & $20,5 \pm 3,7$ \\
\hline 120 & $36,7 \pm 4,7$ & $15,2 \pm 1,1$ \\
\hline
\end{tabular}

A energia específica variou entre 64,2 e $36,7 \mathrm{MJ} / \mathrm{kg}$ de água evaporada para a secagem infravermelho. A $120^{\circ} \mathrm{C}$, a redução no consumo de energia específico foi de aproximadamente $43 \%$ quando comparado à menor temperatura de $80^{\circ} \mathrm{C}$. Conforme verificado anteriormente, maiores temperaturas da fonte de aquecimento infravermelho contribuem para reduzir o tempo de secagem e consequentemente para uma menordemanda de energia.

No trabalho de Reis et. al. (2002), foi avaliado o potencial de caroços de açaí para a produção de energia. O poder calorífico do resíduo obtido foi em média de $4.500 \mathrm{kcal} / \mathrm{kg}$, o que levou os autores a concluírem como viável o uso da biomassa de caroços de açaí como fonte de energia. No entanto, nenhuma análise foi direcionada sobre o consumo de energia durante o processo de secagem realizado em estufa a $110^{\circ} \mathrm{C}$. Considerando um valor-padrão de $220 \mathrm{~W}$ de potência dissipada por uma estufa a esta temperatura e o tempo de 4 horas para se atingir 8-10\% de umidade (de acordo com os dados reportados), o consumo de energia fica em torno de 158,4 $\mathrm{MJ} / \mathrm{kg} \mathrm{H} 2 \mathrm{O}$ e 105,6 MJ/kg de sólido seco. Logo, comparado à secagem convectiva em estufa convencional, a secagem IV reduziu o consumo de energia específica (em MJ/kg H2O) entre 60 e $77 \%$. 
Ao comparar o consumo de energia do processo de secagem IV por unidade de sólido seco com o valor do poder calorífico dos caroços de açaí, verifica-se que a temperatura de operação de $120^{\circ} \mathrm{C}$ é a única, dentre as investigadas, adequada para um balanço de energia favorável, mas representando ainda uma parcela significativa, cerca de $80 \%$, da energia que pode ser gerada pela biomassa.

\section{CONCLUSÕES}

A secagem IV em camada fina de caroços de açaí foi acompanhada por significativas reduções de volume e área superficial das partículas, em torno de 26 e $18 \%$, respectivamente.

Ao considerar a variação da área de transferência de calor e massa sofrida pelo material durante o processo, verifica-se que o comportamento cinético da secagem infravermelho de caroços de açaí em camada fina foi caracterizado por ocorrer nos períodos de aquecimento e a fluxo decrescente, em toda faixa operacional investigada. A transferência de massa foi controlada, portanto, pela resistência interna, ou seja, pela difusão de umidade no interior do material.

A aplicação de radiação IV para a secagem de caroços de açaí resultou numa redução do consumo de energia específica, entre 106 e 158\%, quando comparada com a secagem convectiva. No entanto, apenas a secagem utilizando a temperatura da fonte IV de $120^{\circ} \mathrm{C}$ mostrou-se adequada para um balanço de energia favorável, com o consumo de energia representando cerca de $80 \%$ da energia que pode ser gerada a partir da biomassa seca.

\section{REFERÊNCIAS}

BARBOSA NETO, A. M.; MARQUES, L. G.; PRADO, M. M.; SARTORI, D. J. M. Mass Transfer in Infrared Drying of Gel-Coated Seeds. Advances in Chemical Engineering and Science, v. 4, n. 1, p. 39-48, 2014.

BOUDHRIOUA, N.; BAHLOUL, N.; BEN, I. B.; SLIMEN, N. K. Comparison on the total phenol contents and the color of fresh and infrared dried olive leaves. Industrial Crops and Products, v. 2, n. 2/3, p. 412-419, 2009.

FASINA, O.; TYLER, B.; PICKARD, M.; ZHENG, G.; WANG, N. Effect of infrared heating on the properties of legume seeds. International Journal of Food Science and Technology, v. 36, p.79-90, 2001.

GONZÁLEZ, J. F.; LEDESMA, B.; ALKASSIR, A.; GONZÁLEZ, J. Study of the influence of the composition of several biomass pellets on the drying process. Biomass and Bioenergy, v. 35, p. 4399-4406, 2011.

KALIYAN, N.; MOREY, R. V. Factors affecting strength and durability of densified biomass products, Biomass and Bioenergy, Vol. 33, pp. 337-359, 2009.

KHAN, A.A, DE JONG, W, JANSENS, P. J., SPLIETHOFF, H. Biomass combustion in fluidized bed boilers: potential problems and remedies. Fuel Process Technology, Vol. 90(1), pp. 21-50, 2009.

LIU, Y.; AZIS, M.; KANSHA, Y.; BATTACHARIA, S.; TSUTSUMI, A. Application of the self-heat recuperation technology for energy saving in biomass drying system. Fuel Processing Technology, Vol. 117, PP. 66-74, 2014.

NAGAISH, T. Y. R. AÇAÍ (Euterpe oleracea Mart): extrativismo, características, energia e renda em uma comunidade na Ilha de Marajó/ PA. Dissertação de Mestrado, Universidade Federal Rural da Amazônia, 115p., 2007.

NIAMNUY, C.; NACHAISIN, M.; POOMSA, N.; DEVAHASTIN, S. Kinetics modeling of drying and conversion/degradation of isoflavones during infrared drying of soybean. Food Chemistry, v. 133, n. 3, p. $946-$ 952, 2012.

REIS, B. O.; SILVA, I. T.; SILVA, I. M. O.; ROCHA, B. R. P. Produção de briquetes energéticos a partir de caroços de açaí. Trabalho AGRENER 2002 - 4o Encontro de Energia no Meio Rural, outubro de 2002, Campinas-SP.CD

WANG, L.; WELLER, C.L.; JONES, D.D.; HANNA, M.A. Contemporary issues in thermal gasification of biomass and its application to electricity and fuel production, Biomass and Bioenergy, v. 32, pp. 573-581, 2008. 